\title{
Ideologia esportiva e formação do indivíduo: contribuições da Teoria Crítica do Esporte
}

\author{
Ricardo Casco* \\ Universidade de São Paulo, Instituto de Psicologia. São Paulo, Brasil
}

Resumo: Este ensaio apresenta o debate empreendido em meados da década de 1960, na França, pelo movimento teórico e político denominado Teoria Crítica do Esporte. Essa perspectiva ocorreu em meio ao clima cultural emergente naquele período, marcado pela crítica às instituições vigentes e propunha o desvelamento dos elementos subjacentes à hegemonia da ideologia esportiva na cultura, particularmente na mídia, nos clubes e escolas. O texto apresenta os principais argumentos de seus idealizadores, sobretudo os concebidos por JeanMarie Brohm, aproximando suas inquietações com contribuições oriundas de autores que marcaram a primeira geração da Teoria Crítica da Sociedade, notadamente Theodor W. Adorno, Max Horkheimer e Hebert Marcuse. $\mathrm{O}$ ensaio incide sobre as críticas tecidas por esses autores com a finalidade de compreender os fundamentos do movimento esportivo, concebido como objeto cultural de ampla disseminação e importância para a formação do indivíduo sob a égide do capitalismo.

Palavras-chave: teoria crítica do esporte, teoria crítica da sociedade, ideologia esportiva, formação do indivíduo.

\section{Introdução}

$\mathrm{O}$ alarido ensurdecedor da massa inebriada pela pirotecnia cuidadosamente planejada, os desfiles glamourosos de ícones esportivos renomados durante a abertura dos Jogos Olímpicos do Rio de Janeiro, de 2016, assim como na Copa do Mundo de Futebol, ocorrida no Brasil em 2014, seguidos por olhos atentos de bilhões de telespectadores espalhados pelo planeta, não deixam pairar qualquer dúvida sobre o impacto que têm os eventos esportivos sobre a vida cotidiana contemporânea.

Os momentos fugazes de entorpecimento coletivo, proporcionado ao custo de bilhões de dólares, cumprem, entre outros elementos, ao menos três objetivos claros: operar a dissimulação da barbárie cotidiana que assola a vida do homem comum que habita as cidades e os campos dos mais diversos países; aumentar o lucro de poderosas empresas multinacionais, responsáveis pelas grandes transformações urbanas de cidades das nações organizadoras e pela produção dos bens de consumo identificados com o ideário esportivo; desviar a atenção de grande parcela da população das atrocidades cometidas contra a liberdade e a dignidade humana, tais como as restrições ao acesso à informação ou o exercício da repressão contra movimentos de oposição política. Nesse sentido, a Olimpíada do Rio de Janeiro é análoga a outros eventos esportivos de massa, como a Olimpíada de 1936, que teve lugar em Berlim durante a ascensão nazista, às Copas do Mundo de futebol de 1970, realizada no México e de 1978, na Argentina, as duas últimas ocorridas em meio às atrocidades promovidas pelas ditaduras militares no Brasil e na Argentina, e à Olimpíada de Moscou de

* Endereço para correspondência: cascoricardo@gmail.com
1980, que se deu em meio à deportação de políticos oposicionistas ao regime totalitário para os campos de trabalho forçado - os gulags.

Tendo em vista a importância que o movimento esportivo ocupa na sociedade contemporânea, o objetivo deste texto é dar a ver o debate empreendido pela Teoria Crítica do Esporte, perspectiva teórica e política crítica à hegemonia da ideologia ${ }^{1}$ esportiva na cultura, desenvolvida na França em meados da década de 1960. Objetiva também apresentar as contribuições de autores da Teoria Crítica da Sociedade, sobretudo T. W. Adorno e M. Horkheimer, para a compreensão sobre algumas das associações que se dão entre a formação do indivíduo, o movimento esportivo contemporâneo, o capitalismo, a dominação social e a formação do indivíduo. Devido à amplitude do projeto de pesquisa empreendido pela Teoria

1 Considera-se, neste texto, o conceito de ideologia apresentado por Horkheimer e Adorno (1956/1973): "Com a crise da sociedade burguesa, também o conceito tradicional de ideologia parece ter perdido o seu objeto. O mundo dos produtos espirituais desintegra-se por um lado, na verdade crítica, que se despe do elemento de aparência mas é esotérica e alheia às ligações sociais imediatamente operantes; e, por outro lado, na administração planejada do que, em dado momento, constituiu a ideologia. Se esta herança da ideologia for entendida como totalidade dos produtos espirituais que hoje enchem, em grande parte, a consciência dos homens, então essa totalidade manifestar-se-á, sobretudo, como um conjunto de objetos confeccionados para atrair as massas em sua condição de consumidoras e, se é possível, para adaptar e fixar o seu estado de consciência e não tanto como espírito autônomo inconsciente das próprias implicações societárias. A falsa consciência de hoje, socialmente condicionada, já não é espírito objetivo, nem mesmo no sentido de uma cega e anônima cristalização, com base no processo social; pelo contrário, trata-se de algo cientificamente adaptado à sociedade. Essa adaptação realiza-se mediante os produtos da indústria cultural, como o cinema, as revistas, os jornais ilustrados, rádio, televisão, literatura de best-seller dos mais variados tipos, dentro da qual desempenham um papel especial as biografias romanceadas" (p. 200-201). 
Crítica do Esporte, este texto foi organizado em tópicos que procuram expressar suas principais contribuições.

\section{Teoria Crítica do Esporte: principais formulações}

Na primeira metade da década de 1960, segundo Escriva e Vaugrand (1996), reúnem-se em torno de Michel Bernard, então professor de filosofia em Nanterre, um grupo de estudantes da Escola Normal Superior de Educação Física de Paris. Militantes da extrema esquerda participam de intensos debates sobre Educação Física e Esportes, organizando juntamente com Jean-Marie Brohm, Christian Lidove, Françoise Longone, Jean-Pierre Famose e, posteriormente, Pierre Laguillaumie, Ginette Berthaud, Dominique Robert e Guy Bonhomme, o grupo da "Tendência do Manifesto". O grupo participaria das lutas internas no Sindicato Nacional de Educação Física, entre 1963 e 1964. O grupo mantinha contatos íntimos com a Organização Comunista Internacional. JeanMarie Brohm, um expoente desse grupo, traduz em 1966, juntamente com Boris Fraenkel, a obra Lenine de Georg Lukács e a obra de Wilhelm Reich: A luta sexual dos jovens (reeditada em 1972, na Petite Collection Maspero). A influência das teses freudo-marxistas marcaria profundamente todo o movimento liderado por Jean-Marie Brohm, tornando-se o eixo fundamental de uma longa produção teórica que se destacaria pela crítica virulenta à instituição esportiva.

Segundo Escriva e Vaugrand (1996), em 1968, sob o impacto dos movimentos anti-institucionais em Paris, é lançado o número 43 da revista Partisans, intitulado Sport, culture e répression. No prefácio da revista, em edição espanhola, Berthaud e Brohm (1972/1978) anunciam seu objetivo:

Nuestra intervención se propuso hacer salir a luz la razón de la institución deportiva, es decir, el conjunto de las fuerzas sociales, económicas, políticas e ideológicas que la atraviesan y le dan su dimensión histórica, fuerzas que precisamente la institución tiene por misión negar. En particular, el análisis de los fenómenos del poder, de los sistemas de acción, de decisión, del control y de negación de la institución deportiva, no deja duda alguna acerca de que el deporte indica un proceso de integración social dentro del marco de una relación de fuerzas. (p. 12)

Participantes do movimento que eclodia em 1968, o grupo tem como propósito o desvelamento do que residia escondido nas instituições, referindo-se mais particularmente à análise institucional do esporte. Para seus autores, o esporte teria a função de veicular as ideologias dominantes, suas estruturas, seu imaginário e seus mitos. A crítica radical ao esporte, após Maio de 1968, assume o embate político, denunciando a utilização ideológica do esporte pelo Estado. Durante esse período, o então ministro da juventude, M. Roland Nungesser, sugere a ampliação do movimento esportivo como antídoto à dissolução dos costumes, uma luta contra a desagregação da moral da Nação. Essa posição foi amplamente criticada pelos autores que se reuniam em torno da revista Partisans.

Em 1969/1970, com a ruptura da "Tendência do Manifesto", um grupo de professores militantes de educação física cria o polo da École Émancipée, que lutará no seio do Sindicato Nacional de Educação Física por uma crítica radical, tendo como objetivo a luta de classes (Escriva \& Vaugrand, 1996, p. 30). Em 1975, juntamente com Marc Perelman, Jean-Marie Brohm lança a revista Quel Corps? que duraria 20 anos, publicando o total de 52 números. A revista desenvolveu, entre outras temáticas, uma produção crítica e virulenta ao fenômeno esportivo, entendido como um fato social total, ocupando diversas esferas da organização social - as instituições políticas, econômicas, sociais, jurídicas e demográficas (Arnoud, 1996). Porém, em meados da década de 1980, essa vertente se enfraquece, sobretudo mediante a ascensão de perspectivas teóricas culturalistas em solo francês, bem como devido à crítica às suas formulações consideradas unilaterais, pois não teriam levado em conta, segundo seus detratores, os potenciais humanos e emancipatórios do esporte, como o fair play ${ }^{2}$ e a importância da emergência de novos modelos de relações sociais ${ }^{3}$.

A revista Quel Corps? foi responsável pelos movimentos que organizariam os boicotes à Copa do Mundo de Futebol, em 1978, na Argentina, às Olimpíadas de 1980, em Moscou e aos encontros esportivos na África do Sul, país do Apartheid, denunciando a cumplicidade das organizações esportivas com a violência armada instaurada contra as populações desses países. Segundo Ardoino (1996), a perspectiva empreendida pelas correntes esquerdistas, na França e na Alemanha, no período de 1967 até meados da década de 1980, visou decifrar e denunciar as mazelas empreendidas pelas estruturas definidas na cultura que ao enaltecer a virtude esportiva, a ambição do rendimento e da performance, empreendem a manutenção da ordem social e instituem uma naturalização do movimento esportivo como algo eterno e trans-histórico. Tal vertente teórica se apoia sobre uma tríplice influência: Marx, a Escola de Frankfurt e Freud. Encontra apoio, também, na produção teórica desenvolvida pela análise institucional e em Reich, no que concerne ao corpo (Ardoino, 1996, p. 16). Tal produção teórica visa descortinar uma série de reflexões que se destinariam a compreender o significado e as implicações sociais, econômicas, psicossociais e educacionais que afetam nossa sociedade, como decorrência desse fenômeno de envergadura presente na cultura.

\footnotetext{
2 Sobre esse aspecto, consultar o texto de Adorno (1995) intitulado "Tabus acerca do magistério".

3 Sobre esse aspecto consultar o texto de Horkheimer (1998) intitulado "Noveaux modèles dans les relations sociales".
} 
Segundo Brohm (1995a), o projeto de pesquisa e crítica, desenvolvido pelo grupo de autores reunidos pela revista Quel Corps?, estrutura-se numa perspectiva de pesquisa que parte da diretriz metodológica que concebe a realidade esportiva "como uma totalidade articulada de instâncias, estratos, tópicos, dimensões, esferas, estruturas, infraestruturas e superestruturas, metáforas, conceitos ou noções que designam a hierarquização de lugares da realidade no seio das totalidades reais em marcha" (p. 88, tradução nossa). $\mathrm{O}$ autor parte de um eixo epistemológico "claro e distinto": a análise da realidade concreta (Brohm, 1995a, p. 89). Para ele, o fenômeno esportivo é entendido como uma totalidade, um conjunto articulado de relações sociais e de instituições determinadas pela organização da competição, estruturadas pelo princípio de rendimento corporal, a produtividade, a rentabilidade e a competitividade (Brohm, 1995a, p. 90).

Seguindo a orientação compreendida pelo método dialético ${ }^{4}$, o grupo de autores reunidos na revista Quel Corps? empreenderá uma ampla investigação visando compreender o fenômeno esportivo em sua totalidade ${ }^{5}$. Essa opção recai numa tentativa de propor a sociologia de investigação, e não a sociologia de gestão (Quel Corps?, 1995). O entendimento do objeto em sua articulação com o todo social, dotaria a Sociologia de um caráter revolucionário à medida que, empreendendo a crítica, recuperaria o seu potencial de intervenção na vida social. De tal forma, a análise empreendida pela Teoria Crítica do Esporte compreende a análise do fenômeno esportivo em quatro frentes distintas. A primeira frente da análise da revista Quel Corps?, segundo Brohm (1995a), se debruçaria sobre os clubes esportivos, as empresas patrocinadoras de eventos esportivos, as associações esportivas e as instituições educativas, analisando as instituições que dão sustentação ao fenômeno esportivo. A segunda frente compreende as práticas esportivas. $\mathrm{O}$ autor procura esclarecer a lógica da competição esportiva que compreenderia a lógica perversa de efeitos perversos: a manipulação psicobiológica, a utilização de doping, a modelização informatizada dos comportamentos e técnicas, acidentes, traumatismos e a produção de corpos cibernéticos como ideal a ser atingido. A terceira frente remete ao estudo dos eventos esportivos. O autor analisa os grandes encontros internacionais, seus poderes encantatórios e mistificadores que instituem, em última análise, o nacionalismo, a xenofobia e o chauvinismo. Nesse ponto, Brohm (1995a) reconhece algumas funções

4 Os formuladores da Teoria Crítica do Esporte utilizam o conceito de dialética conforme anunciado por Marx no prefácio da segunda edição de O Capital: crítica da economia política (Cf. Brohm, 1996,).

5 Para Karel Kosik (citado em Quel Corps?, 1995, p. 90): "A totalidade concreta significa a 'realidade como conjunto estruturado e dialético', no qual - ou a partir do qual - os fatos, quaisquer que sejam (grupo ou conjunto de fatos), podem ser compreendidos racionalmente. Reunir todos os fatos não é, ainda, conhecer a realidade, e todos os fatos (reunidos) não constituem, ainda, a totalidade. Os fatos permitem uma compreensão da realidade se eles são concebidos como fatos de uma totalidade dialética, como partes, estruturando a totalidade, e não como átomos imóveis, indivisíveis e irredutíveis". do espetáculo esportivo televisivo de massa: o efeito de prestígio nacional e reconhecimento internacional; o efeito de ocultação da realidade sociopolítica (a exemplo de espetáculos esportivos, realizados durante ditaduras militares, na América do Sul, na URSS ou, ainda, as Olimpíadas de 1936 sob o nazismo de Hitler ${ }^{6}$ ); o efeito de massificação e identificação coletiva à ordem estabelecida - ao que o autor define como uma função gregária ou consensual que permite a ascensão de ídolos e de grupos; o efeito de diversão ideológica, cumprindo certa função narcótica e, por fim, o efeito de compensação pulsional e gratificação narcísica. A última frente de análise remete aos discursos esportivos, por parte da mídia esportiva e dos representantes políticos, eminentes no período histórico estudado, entre eles Pierre de Coubertin.

\section{A crítica ao ideário esportivo de Pierre de Coubertin}

Um dos traços mais significativos da utilização ideológica promovida pelo ideário esportivo refere-se à tentativa de dotá-lo de atributos trans-históricos. Para os seus ideólogos, a restauração dos ideais de "lealdade", "honra", virtudes dos Jogos Olímpicos da Antiguidade grega, dotaria o esporte moderno de potencialidades humanas necessárias para a harmonização das tensões entre os povos e para a unificação e manutenção da ordem nacional. Quel Corps? (1995) denomina este grupo de autores como reformistas do esporte. Esses autores, partindo de uma visão anacrônica, visaram instaurar um modelo esportivo dotado de virtude e ética. Buscaram resgatar os atributos presentes na moral dos Jogos Olímpicos da Antiguidade em prol do desenvolvimento do esporte moderno. Pierre de Coubertin foi o principal fomentador desse ideário ao promover os primeiros Jogos Olímpicos da Era Moderna.

Segundo Quel Corps? (1976), Pierre de Coubertin, nascido em $1^{\circ}$ de janeiro de 1863 , filho da aristocracia parisiense, viria a se tornar o principal fomentador, também, do desenvolvimento de uma pedagogia esportiva nas escolas. Coubertin havia tomado conhecimento da iniciativa pedagógica empreendida por Thomas Arnold, na Inglaterra, estruturada sobre a educação esportiva voltada para a formação de atletas e para uma educação moral destinada a formar cristãos. Empolgado com a reforma pedagógica inglesa, visita a Inglaterra em 1883 para verificar de perto os progressos empreendidos por Arnold. De volta à França, Coubertin pretende, de um lado, desenvolver uma educação que preparasse os filhos da burguesia para o struggle for life internacional e, de outro, assentar, graças à ideologia esportiva (fair play, o respeito às regras estabelecidas etc.), a paz social.

Segundo Quel Corps (1976, p. 26), em 1888, Coubertin preside o "Comitê para a preparação dos

6 Sobre essa questão, consultar também Brohm (1995b). 
exercícios físicos na educação", tendo como objetivo o desenvolvimento do esporte escolar e a organização de competições esportivas. Esse comitê tornar-se-ia, em 1889, a União Esportiva Francesa de Esportes Atléticos, auxiliando a formulação dos programas direcionados à escola, tornando-se o embrião de uma reforma pedagógica que integraria a Educação Física e o esporte no ensino escolar. Para Coubertin, o desenvolvimento do esporte seria a contribuição que a burguesia poderia oferecer à formação de um operariado mais sadio, capaz de enfrentar os problemas ocasionados pelo desenvolvimento urbano e o desenvolvimento industrial. Coubertin objetivava não apenas a formação de operários mais robustos, saudáveis e resistentes, visando o aumento de produtividade, como também apreciava o desenvolvimento do esporte como fator de estabilidade social. Segundo Quel Corps (1976), ao visitar os EUA em 1889, Coubertin toma contato com Theodore Roosevelt e seu programa de boxe nos bairros mais problemáticos (visando a diminuição da violência), comprovando a tese do esporte como fator de estabilidade da ordem social.

Segundo a revista Quel Corps? (1976) em 1894, o comitê geral da USFSA ${ }^{7}$, decide apoiar o restabelecimento dos Jogos Olímpicos analisando que "não há dúvida sobre as vantagens que apresentam o restabelecimento dos Jogos Olímpicos para o atletismo bem como para a moral" (p. 26). Coubertin, após ter ganho uma medalha de ouro em literatura, nos Jogos Olímpicos de 1912, realizados em Estocolmo, com o poema "L'Ode au sport", é encarregado pelo então ministro de L'instruction Publique, Albert Sarraut, em 1915, a percorrer os liceus franceses para estimular a formação física e muscular dos alunos como preparação para a longa duração da I Guerra Mundial (1914-1918). No mesmo ano, Coubertin publicaria Aux jeunes français, le Décalogue de 1915, no qual incita a juventude para o desenvolvimento pelo esporte e a defesa da civilização francesa. Com o fim da guerra, em 1918, o marechal Lyautey escreve a Coubertin, considerando-o um dos responsáveis pelo triunfo devido ao treinamento esportivo da juventude francesa. Para Coubertin, o esporte auxiliaria a educação moral da juventude, preparando-a para as batalhas da vida. Em suas palavras: "O desenvolvimento muscular e o treinamento corporal constituem para o adolescente de hoje a salvaguarda moral mais ativa e a valorização mais fecunda de sua personalidade" (Quel Corps?, 1976, p. 28).

Além de corresponder à educação moral e à saúde corporal, o esporte cumpriria a função de racionalizar a imaginação da juventude, preparando-a para o cumprimento das expectativas socialmente ordenadas. Coubertin via, no esporte, um elemento apaziguador dos interesses dispersos e conflituosos entre a juventude burguesa e a juventude proletária, contribuindo para melhorar as relações entre os diferentes extratos sociais, em prol de colaborações mais eficazes.

7 Union Sportive Française de Sports Athlétiques.

\section{O esporte e o desenvolvimento tecnológico}

O desenvolvimento do esporte moderno não parece passível de entendimento sem a compreensão do próprio desenvolvimento científico tecnológico, que constitui uma de suas bases. Um de seus resultados aparece como o desenvolvimento de técnicas de treinamento esportivo: o homem reduz-se às metáforas da máquina que, numa análise política, reduzem os processos vivos a processos energéticos e econômicos de produção, o corpo é inteiramente planificado e positivado. Para Laguillaumie (1996),

como toda realidade social, o esporte se inscreve no quadro de relações de produção que determinam fundamentalmente sua estrutura interna. Atualmente o esporte é determinado pela sociedade capitalista por relações de classe. Mas, como prática social de um tipo determinado, o esporte é condicionado pelo desenvolvimento das forças produtivas. $\mathrm{O}$ esporte moderno está ligado ao advento do maquinário industrial e ao tipo científico, técnica de organização da produção. O esporte moderno está então, definitivamente, em todos os seus fenômenos e manifestações, ligado estruturalmente a uma base econômica, a uma infraestrutura dada: as relações de produção capitalistas industriais. (p. 75, tradução nossa)

O fenômeno esportivo é compreendido como um produto definido pelas relações de produção do sistema capitalista industrial. Essa determinação imprime um caráter revelador no que concerne a sua estrutura e ideologia, servindo para a manutenção do ideário dominante, condicionado pelas forças produtivas identificadas com o enaltecimento da técnica e o maquinismo industrial, elementos que conferirão uma relação com o corpo de caráter técnico-positivista, estruturalmente ligada à base econômica.

Para Brohm (1992), "pela revolução científica e técnica, o corpo entra na era tecnológica, na era do maquinário industrial. O corpo torna-se, pois, ele mesmo, um objeto privilegiado dessa revolução (técnicas e serviços do corpo)" (p. 128). Segundo o autor, com o desenvolvimento industrial e a urbanização, o esporte moderno se desenvolveu à medida que se desenvolviam as forças produtivas com a revolução científica e tecnológica. Com o advento e a expansão de instrumentos tecnológicos ultramodernos, como os aparelhos de medição de tempo (cronômetro), o esporte ganha subsídios que facilitariam sua expansão.

O surgimento de novas técnicas de treinamento esportivo advém do conhecimento científico. O desenvolvimento de novas tecnologias, como aparelhos para medir o tempo, assim como a tecnologia para remanejamento de espaços destinados à melhoria da 
performance esportiva, constituem condições para que o próprio esporte moderno possa se desenvolver não mais como manifestações isoladas de grupos restritos. Com a padronização dos instrumentos de medição surgem critérios que podem ser ampliados para outros grupamentos, em outras regiões, possibilitando a codificação dos objetivos a serem atingidos em cada modalidade esportiva, podendo ser compartilhados entre grupos distantes, em países distintos, dando início ao que mais tarde se configuraria como a padronização do esporte em escala global.

O desenvolvimento científico-tecnológico compreende a aquisição de novos métodos de treinamento e instrumentos precisos para a aferição da performance, eixo fundamental para a organização esportiva (Laguillaumie, 1996). O recorde refere-se à abstração do rendimento corporal, instituído pelo desenvolvimento de medidas objetivas. O corpo matematizado, quantificado, controladas as suas funções fisiológicas, é desumanizado em prol do rendimento e da performance. A submissão corporal ao controle científico passa a ser a marca do esporte moderno. Para Ellul (1995), o desenvolvimento tecnológico empreende uma mudança no universo das práticas esportivas. Para o autor,

é necessário de início compreender que houve uma mudança social do esporte devido ao espírito da técnica, quer dizer, devido aos valores que a sociedade tecnificada desenvolveu. . . Um valor decisivo que domina nosso tempo é o sucesso devido à competitividade. Ora, isso é derivado diretamente da técnica: ela é sempre a procura do melhor meio para alcançar certo resultado. A técnica é antes de tudo um cálculo de sucesso e de vitória. (Ellul, 1995, p. 128, tradução nossa)

$\mathrm{O}$ autor analisa que o esporte, considerado inicialmente um jogo, compreendia o ideal de ganhar, embora não fosse obsessivo. A vitória era relacionada ao prazer e à honra. Outra característica importante refere-se a seu limite geográfico. Somente com o advento do desenvolvimento científico foi possível uma unificação dos padrões de medida que possibilitaram a sua internacionalização, conferindo à imagem do esportista um caráter mundial pela comparação objetiva das performances dos melhores resultados. A tecnificação do meio esportivo não se resume apenas ao desenvolvimento de todo o aparato tecnológico instrumental, diz respeito também às técnicas desenvolvidas junto à psicologia, à comunicação, ao treinamento desportivo, à biologização e à aproximação do corpo humano à máquina.

Para Ellul (1996), com a primazia da técnica

o homem torna-se nesse domínio também um tipo de máquina, sua atividade controlada por aparelhos torna-se técnica. A civilização técnica encontra, dessa forma, seu auge nessa mecanização. Pela disciplina esportiva, o homem não somente joga e diminui as tensões e dificuldades, mas também se adapta sem saber, se prepara para novas dificuldades. (p. 140, tradução nossa)

Para Brohm (1992), o desenvolvimento do cronômetro e a busca de recordes são dois elementos que alçariam o fenômeno esportivo ao próprio desenvolvimento industrial, revestindo-o de outros elementos marcadamente distanciados do que, em outra época, definia o culto às divindades e à concepção de corpo condicionada à metafísica da finitude. Tais elementos diferem do que parece ser no desenvolvimento do esporte moderno o seu correlato oposto: o desejo de superação da própria limitação biológica humana, a negação da ideia da morte, presente simbolicamente no culto à ideia de ultrapassar os limites corporais pelo treinamento esportivo e que encontra no fetiche do recorde uma de suas expressões. A glorificação do conhecimento científico-tecnológico parece confundir-se com o desejo do homem de ultrapassar o espectro da morte. O esporte moderno expressa o desejo da vida eterna, a renúncia da finitude corporal. O culto ao corpo, último reduto diante do envelhecimento ameaçador, é corroborado pelo desenvolvimento tecnológico-científico que acaba por invadir todas as esferas do desenvolvimento social humano.

O esporte moderno, ao estabelecer uma unidade organizacional baseando-se no recorde ${ }^{8}$ como referência, forja um caráter universal constituindo elementos concretos e objetivos para a comparação entre as performances corporais. Unificando o sistema esportivo em regras universais, o recorde confere ao esporte um caráter internacional, corroborando o ideal liberal burguês que ao fortalecer a estrutura hierárquica, inerente ao modelo esportivo, fortalece as relações de dominação de classe, concebendo o esporte como uma instituição concreta que propõe cooperação fraternal entre os povos, auxiliando a promoção da ideologia da humanidade esportiva: "a comparação universal é possível, a confrontação pacífica esportiva pode jogar seu papel político da união dos povos" (Lauguillaume, 1996, pp. 75-76). Os autores da Teoria Crítica do Esporte chamam a atenção, também, para a naturalização da hierarquia corporal, própria do ideário esportivo.

\section{Notas sobre a hierarquia corporal}

A hierarquia corporal corresponde à instituição de rituais de passagem, agrupamento por níveis de habilidade e à divinização dos atletas esportivos de renome (o campeão esportivo). A hierarquia por habilidade corporal corrobora as funções adaptativas e normatizadoras de um status quo baseado na violência e adestramento

8 Para Ellul (1995), "O recorde torna-se um tipo de valor em si, da mesma ordem que a vitória de uma equipe sobre a outra nos esportes de competição. Mas isso atesta somente o triunfo da técnica sobre o corpo" (p. 132, tradução nossa). 
corporais, que no conjunto social remetem a conteúdos pouco esclarecidos. A hierarquia baseada na habilidade corporal tem o desenvolvimento do modelo esportivo uma de suas inspirações. O esporte estrutura-se na figura do campeão esportivo, a elite dos corpos treinados. Esse ideário já havia sido claramente delineado pelo seu mais famoso reformador, Pierre de Coubertin. Para o autor,

para que cem possam se consagrar à cultura física, é preciso que cinquenta pratiquem esporte. Para que cinquenta possam praticar esporte, é preciso que vinte se especializem (em competição). A fím de que vinte se especializem, é preciso que cinco sejam capazes de performances espantosas. (citado por Brohm, 1992, p. 92, tradução nossa)

Para Brohm (1992), o esporte é a poesia corporal da hierarquia, fundamentando-se na hierarquização de performances que são comparáveis à luz de medidas objetivas, estruturadas sob o modelo competitivo. A imagem do campeão é a referência absoluta que encarna o ideal esportivo, sendo o próprio motor do desenvolvimento da técnica esportiva. Apoiado sob um sistema objetivo de medidas e treinamentos estandardizados, o campeão esportivo define as imagens dos corpos sobre os quais se operam as identificações da massa. Para Lauguillaume (1996), o esporte como fator de socialização e educação constitui o mesmo papel que outrora ocupavam a família e a religião na estruturação das pulsões do ego e, sobretudo, a estruturação do superego. Brohm (1992) já havia problematizado a importância conferida à imagem do corpo para a estruturação das identificações fornecidas pela mass media. $\mathrm{O}$ autor assinala que "a sociedade se interioriza, se incrusta nas emoções e movimentos dos indivíduos. Com efeito, pela modificação da consciência do eu muscular que opera a influência da sociedade sobre o indivíduo" (Brohm, 1992, p. 262).

Incorporando análises feitas por Stoezel (1963), Brohm (1992) compartilha a afirmação de que a imagem do corpo é uma construção social, tendo uma consequência política importante: a imbricação estrutural entre o corpo-organismo e o corpo social concebido sobre um modelo. $\mathrm{O}$ autor apoia seus argumentos em Marcuse, em Eros e civilização, quando este afirma que "a materialização corporal do superego é acompanhada da materialização corporal do ego que se manifesta por traços e gestos estereotipados" (Marcuse, 1963, p. 96), para afirmar o esporte como produto cultural característico da sociedade industrial.

Ao constituir, pela mass media, modelos idealizados e distantes da vida real, a indústria cultural acaba por conceber modelos aos quais os indivíduos não podem se contrapor devido à falta de proximidade real, o que poderia levar à superação do próprio ideal possibilitando se diferenciarem e não apenas reproduzirem sempre o mesmo. Para Brohm (1992), a identificação não é mais personalizada e mediatizada pela figura paterna, mas por figuras coletivas de autoridade e eficácia fornecidas pela indústria cultural ${ }^{9}$.

Brohm (1992), apoiando-se em Adorno (1969/1995), observa ainda que as atividades esportivas são estruturadas sob a forma de pseudoatividades ${ }^{10}$. O esporte, assim compreendido, propõe ao indivíduo uma falsa unidade entre o particular e o universal. A impossibilidade da liberdade requerida pelo indivíduo é atenuada pela solicitação da adesão irrefletida ao todo social, o que confere ao indivíduo um falso sentimento de bem-estar compensatório. A pseudoatividade não altera aquilo que é negado pela própria organização social, ao contrário, fortalece a ideologia que mantém a consciência em constante estado de regressão.

Para Berthaud (1996),

o sistema esportivo, por seus objetos e suas manifestações, oferece aos indivíduos um suporte de investimento libidinal particular que merece ser analisado, não seria assim que por sua aptidão para "fixar" as pulsões menos sociais (sexualidade, agressividade) em seus setores visando assegurar a coesão do conjunto social. (p. 214, tradução nossa)

Freud (1929/1997), em O mal-estar na civilização, já havia apontado para a função conferida aos objetos parciais instituídos pela cultura. Os objetos culturais constituem-se em objetos parciais e favorecem a troca das finalidades originárias pulsionais, operação fundamental para a manutenção da coesão do conjunto social. O esporte pode ser entendido como um elemento compensatório aos limites impostos pela vida cotidiana. A atividade esportiva oferece uma coletivização de satisfações substitutivas (Brohm, 1992) que preparam os indivíduos para melhor suportar o que no ordenamento social lhes é recusado. O esporte converge, assim, para a manutenção da unidade social, desviando ou substituindo os potenciais agressivos ou sexuais reprimidos, transformando-os em atividade inofensiva.

Assim sendo, é possível compreender como o esporte atua sobre a formação da subjetividade, ao instituir modelos corporais que passam a cumprir

9 Sobre o status do conteúdo ideológico do esporte, Horkheimer e Adorno (1956/1973) comentam: "O estudo concreto do conteúdo ideológico da comunicação de massa é tanto mais urgente quando se pensa na inconcebível violência que os seus veículos exercem sobre o espírito dos homens, em conjunto, diga-se de passagem, com o esporte, que passou a integrar, nos últimos tempos, a ideologia, em seu mais amplo sentido" (p. 202).

10 Segundo Adorno (1969/1995), "pseudo-atividade é espontaneidade mal orientada. Mal orientada, mas não por acaso, e sim porque as pessoas pressentem surdamente quão difícil seria para elas mudar o que pesa sobre seus ombros. Preferem deixar-se desviar para atividades aparentes, ilusórias, para satisfações compensatórias institucionalizadas, a tomar consciência de quão obstruída está hoje tal possibilidade. . . Parece evidente a hipótese, entre outras, de que mediante os esforços requeridos pelo esporte, mediante a funcionalização do corpo no 'team', que se realiza precisamente nos esportes prediletos, as pessoas adestram-se sem sabê-lo para as formas de comportamento mais ou menos sublimadas que delas se espera no processo do trabalho" (p. 78-79). 
a função de ideal do ego, aos quais o ego deve se identificar. Segundo Berthaud (1996): "o objetivo é permitir às pulsões se cristalizarem sobre objetos nos quais vem se abolir a força explosiva do desejo" (p. 219, tradução nossa). O esporte atua como um dos objetos culturais que cumprem o papel de canalizar a sexualidade reprimida na organização social repressiva. Para a autora, "as atividades corporais são fontes de angústia, tanto para aqueles que as praticam como para aqueles que as dirigem" (Berthaud, 1996, p. 220). Se o princípio de realidade impõe-se pela cultura, as pulsões libidinais carregam o espectro de algo terrível, levando o indivíduo a proteger-se daquilo que gera angústia. $\mathrm{O}$ controle corporal proferido pelo esporte configura-se numa espécie de anteparo à irrupção da angústia concernente à possível liberação das pulsões sexuais. O esporte ofereceria um excelente derivativo capaz de desviar as pulsões de seu objeto inicial. Configura-se como objeto, culturalmente valorizado e útil para a unidade social ameaçada pela liberação das pulsões ameaçadoras: "o esporte é uma atividade sexual socialmente aceita" (Berthaud, 1996, p. 219, tradução nossa). O esporte constitui-se como um substitutivo, desviando o prazer sexual para outros que não suscitariam nem angústia nem culpabilidade excessivas.

Para a ordem estabelecida, a violência regrada pela atividade esportiva é aceita como fato inerente às competições. Ela não se dirige para a contestação social e não coloca em perigo as normas socialmente constituídas sob a base da repressão dos desejos. Esse dado corresponde à análise realizada por Brohm (1975), ao destacar a correspondência entre a repressão sexual e o fortalecimento da pulsão de morte. Para o autor, a pulsão sexual enfraquecida não pode mais ligar a pulsão de morte ao trabalho cultural e a morte triunfa, seja simbolicamente pela angústia da população deprimida, seja realmente pela guerra, o crime ou o esporte de competição (Brohm, 1975, p. 167 , tradução nossa).

Por essa ótica, o esporte cumpre um duplo papel: como objeto cultural, a serviço da repressão sexual, reforçando as pulsões destrutivas que se dirigem, no plano interior, para a formação de um superego forte e severo. No plano exterior ao indivíduo, libera as tendências agressivas, podendo assumir formas violentas, algo que se pode destacar no comportamento das torcidas fanáticas nos estádios esportivos ou na violência orientada para a submissão dos mais fracos fisicamente. Brohm (1975) destaca que, quanto maior a repressão sofrida, maior a possibilidade de o indivíduo desenvolver certa tendência a se identificar com as prescrições de superegos mais severos e com normas corporais mais rígidas. Segundo Gantheret (1978), "la apetencia por una 'cultura física', por la musculatura, por el dominio corporal, es manifestación de una fantasía de restauración, de 'reconstitución' y de reunificación del cuerpo que se da entre los sujetos que se sienten en peligro" (p. 87).
Se o esporte se assenta sobre a constituição de corpos fortes e saudáveis, ao mesmo tempo afasta o indivíduo das ameaças representadas pelo descontrole das pulsões, ocultando a repressão necessária para a sua perpetuação. A construção de corpos rígidos e a educação para resistir à dor corporal impelem o indivíduo para a aceitação irrefletida da repressão. Para Brohm (1975), "o indivíduo se forja assim uma fortaleza muscular que representa a defesa corporal contra as pulsões" (p. 165, tradução nossa).

Adorno (1971/1995) destaca a necessidade de extirpar da educação a promoção da virilidade e a resistência à dor. Para o autor,

o elogiado objetivo de "ser duro" de tal educação significa indiferença contra a dor em geral. No que, inclusive, nem se diferencia tanto a dor do outro e a dor de si próprio. Quem é severo consigo mesmo adquire o direito de ser severo também com os outros, vingando-se da dor cujas manifestações precisou ocultar e reprimir. (Adorno, 1971/1995, p.128)

Para Adorno (1971/1995), a manifestação do ideário que promove o medo e a indiferença contra a dor é uma das características do caráter manipulador (destacado do estudo A personalidade autoritária) que, entre outras disposições, desenvolve uma tendência para tratar os outros como massa amorfa, "trata todo o existente como objeto" (Adorno, 1950, p. 715). O caráter manipulador, caracteriza-se por dar importância demasiada aos aspectos técnicos da vida, apoderando-se das pautas tecnológicas como forma de administrar o existente. Segundo o autor, a fetichização da técnica embota a capacidade de amar. O desenvolvimento do ideário esportivo encontra, nas disposições tecnológicas, um de seus suportes mais importantes. A redução do corpo a pautas biológicas ou cibernéticas (modelos de input, output, transmissão de informação, mecanismos perceptivos. . .), a tecnificação do controle do movimento, o desenvolvimento de programas de treinamento exaustivos, baseados na repetição e no esforço máximo, constituem-se elementos fundamentais para o desenvolvimento esportivo. A frieza e a incapacidade total de levar a cabo experiências humanas diretas (Adorno, 1971/1995) são disponibilizadas pela cultura opressiva que favorece o surgimento da falsa projeção ${ }^{11}$, operação na qual o sujeito perde a capacidade de reflexão.

A resistência à dor, "ir até o limite" e mesmo ultrapassar os limites, impele o indivíduo para uma

11 Para Horkheimer e Adorno (1947/1985), "Segundo a teoria psicanalítica, a projeção patológica consiste substancialmente na transferência para o objeto dos impulsos socialmente condenados do sujeito. Sob a pressão do superego, o ego projeta no mundo exterior, como intenções más, os impulsos agressivos que provêm do id e que, por causa de sua força, constituem uma ameaça para ele próprio. Deste modo, consegue livrar-se deles como uma reação a esse mundo exterior, seja imaginariamente pela identificação com o pretenso vilão, seja na realidade sob o pretexto de uma legítima defesa" (p. 179). 
educação que pretende extirpar o que poderia ainda representar traços de humanidade. A propaganda publicitária do "faça você mesmo", o enaltecimento da eficácia ou a propaganda do homem ativo, parecem confluir para a formação no indivíduo de bases sobre as quais o preconceito e a violência se desenvolvem. Adorno (1971/1995) caracteriza o tipo manipulador como fruto de uma consciência coisificada. Para o autor, "no começo as pessoas desse tipo se tornam por assim dizer iguais a coisas. Em seguida, na medida em que o conseguem, tornam os outros iguais a coisas" (p. 130).

Adorno (1969/1973) comenta que "en una sociedad cosificada nada que no se haya a su vez cosificado puede sobrevivir" (p. 17). O resultado do próprio desenvolvimento do modo de produção, a organização, a classificação e ordenação das relações de produção, acabou por invadir todas as esferas das relações humanas. A redução do pensamento ao que é imediato coopera com o próprio princípio de otimização dos recursos que imprimem a dominação e a permanência do espírito humano num estágio de menoridade. O pensamento coisificado não se apresenta apenas como produto do próprio processo de desenvolvimento do modo de produção capitalista capitalismo, mas também como redução metodológica do real que se manifesta nas diferentes áreas da cultura, como na educação.

Para Horkheimer e Adorno (1947/1985), os mecanismos adaptativos levam o homem à submissão cega e irrefletida e a identificar-se com os ideais de consumo padronizados e veiculados pelos meios de comunicação de massa. O indivíduo desenvolve uma forma de pensar e sentir nas suas relações afetivas e de lazer compatíveis com a racionalidade do trabalho alienado. Assim, para os autores, "a racionalidade técnica converte-se na racionalidade da própria dominação. Ela é o caráter compulsivo da sociedade alienada de si mesma" (Horkheimer \& Adorno, 1947/1985, p. 114). A consciência coisificada é a base do autoritarismo e se funda no fetiche da mercadoria ${ }^{12}$, perpetuada em objetos culturais fomentados pela indústria cultural. Ao promover uma falsa reconciliação entre o particular e o universal, a indústria cultural universaliza uma falsa realidade, levando os homens à realização de uma felicidade ilusória.

Por sua vez, o esporte, concebido como pseudoatividade, objeto fetichizado, cultuado e difundido pelos mecanismos da indústria cultural, oferece as condições necessárias para a promoção de valores coletivos que se impõem como modelos corporais e

12 "Marx descreve o caráter fetichista da mercadoria como a veneração do que é autofabricado, o qual por sua vez, na qualidade de valor de troca se aliena tanto do produtor como do consumidor, ou seja, do "homem". Escreve Marx: "o mistério da forma mercadoria consiste simplesmente no seguinte: ele devolve aos homens, como um espelho, os caracteres sociais do seu próprio trabalho, como propriedades naturais e sociais dessas coisas; em consequência, a forma mercadoria reflete também a relação social dos produtores com o trabalho global como uma relação social de objetos existente fora deles" (1932, citado por Adorno, 1999, p. 77-78). valores morais que parecem corresponder aos anseios de integração social. Assim como o corpo é expropriado em função da reprodução do capital pela esfera do trabalho, o princípio de rendimento, representado pela produção de corpos performáticos, corresponde à institucionalização do modo de produção capitalista na esfera do corpo. Para Brohm (1992),

o sistema esportivo não considera a personalidade concreta dos indivíduos, mas sua força de produção de performances. Os indivíduos não são, no esporte personalidades concretas, mas portadores reais ou potenciais de performances, do mesmo modo que o operário não é um homem, mas um agente portador de uma função, de um lugar no processo de produção. O capitalismo é um modo de produção no qual os indivíduos concretos são substituídos por agentes abstratos, números, porta-vozes, relações de produção. (p. 166, tradução nossa)

A performance esportiva corresponde, no mundo do trabalho, ao mesmo processo de despersonalização que destitui o indivíduo daqueles atributos que poderiam conferir-lhe, ainda, algum traço de humanidade. $\mathrm{O}$ indivíduo ao ser reduzido pelo sistema produtivo em potencial reprodutivo da força de trabalho e, no sistema esportivo, à sua capacidade de produzir performances, sucumbe aos processos adaptativos regressivos. $\mathrm{O}$ corpo performático corresponde à redução do indivíduo aos atributos exigidos para a promoção da coesão social. O corpo performático, modelo ideal esportivo, impele o indivíduo para a adequação inconteste à realidade social. Esta, por sua vez, confere importância à corporeidade, dotando-a de valor de troca no sistema produtivo de recordes. Nesses termos, a hierarquização que toma como base a desempenho corporal, ideário também presente nas aulas de Educação Física (Casco, 2003, Daolio, 1995), parece assinalar uma adesão irrefletida ao ordenamento social que por meio de seus bens culturais promove a violência e a dominação dos tidos como mais aptos corporalmente sobre os mais fracos e inábeis. Em sentido contrário, cabe às perspectivas críticas emergentes no interior do debate acadêmico e na vida política a possibilidade de constituir e democratizar o acesso à cultura corporal voltada para a promoção da felicidade humana.

\section{Considerações finais}

A perspectiva teórica encampada pela Teoria Crítica do Esporte mantém sua força política como crítica cultural. Apresenta elementos importantes para a compreensão dos processos encantatórios massivamente veiculados nas instituições sociais, sobretudo pela mídia e pelas instituições educativas. Tal compreensão se faz necessária para a luta política que tem por objetivo o enfrentamento dos processos reificadores e desumanizadores, ainda presentes na vida social. 


\section{Sports ideology and formation of the individual: contributions from the Critical Theory of Sport}

Abstract: This paper presents the debate undertaken in the mid-1960s in France, by the theoretical and political movement called Critical Theory of Sports. This perspective came amid the emerging cultural climate in that period, marked by criticism of existing institutions and proposed the unveiling of the elements underlying the hegemony of sports ideology in culture, particularly in the media, clubs and schools. The text presents the main arguments of its creators, especially those designed by Jean-Marie Brohm, bringing their concerns with contributions from authors that marked the first generation of Critical Theory of Society, notably Theodor W. Adorno, Max Horkheimer and Hebert Marcuse. The test focuses on the criticism leveled by the authors in order to understand the fundamentals of the sports movement, conceived as a cultural object of wide spread and importance to the formation of the individual under the aegis of capitalism.

Keywords: sports, Critical Theory of Sports, critical theory of society, formation of the individual.

\section{Idéologie sportive et la formation de l'individu : contributions de la Théorie Critique du Sport}

Résumé: Cet article présente la discussion menée au milieu des années 1960 en France, le mouvement théorique et politique appelée la théorie critique Sport. Cette perspective est venu au milieu du nouveau climat culturel d'époque, marquée par la critique des institutions existantes et a proposé le dévoilement des éléments sous-jacents à l'hégémonie de l'idéologie de sport dans la culture, en particulier dans les médias, les clubs et les écoles. Le texte présente les principaux arguments de ses fondateurs, en particulier ceux conçus par Jean-Marie Brohm, apportant leurs préoccupations avec les contributions des auteurs qui ont marqué la première génération de la théorie critique de la société, notamment Theodor W. Adorno, Max Horkheimer et Herbert Marcuse. Le test se concentre sur les critiques formulées par les auteurs afin de comprendre les fondements du mouvement sportif, conçu comme un objet culturel de large diffusion et de l'importance à la formation de l'individu sous l'égide du capitalisme.

Mots-clés: sport, Théorie Critique du Sport, théorie critique de la société, formation de l'individu.

\section{Ideología deportiva y la formación del individuo: las contribuciones de la Teoría Crítica de Deporte}

Resumen: En este trabajo se presenta el debate llevado a cabo a mediados de la década de 1960 en Francia, el movimiento teórico y político llamado Teoría Crítica del Deporte. Esta perspectiva se produjo en medio del clima cultural que emerge de ese período, marcado por la crítica de las instituciones existentes y propuso la presentación de los elementos que subyacen a la hegemonía de la ideología de los deportes en la cultura, en particular en los medios de comunicación, clubes y escuelas. El texto presenta los principales argumentos de sus creadores, especialmente los diseñados por Jean-Marie Brohm, con lo que sus preocupaciones con contribuciones de autores que marcaron la primera generación de la teoría crítica de la sociedad, en particular Theodor W. Adorno, Max Horkheimer y Hebert Marcuse. La prueba se centra en las crítica de los autores con el fin de comprender los fundamentos del movimiento deportivo, concebido como un objeto cultural de amplia difusión e importancia a la formación de la persona bajo los auspicios del capitalismo.

Palabras clave: deporte, Teoría Crítica del Deporte, teoría crítica de la sociedad, formación del individuo.

\section{Referências}

Adorno, T. W. (1950). La personalidad autoritaria. Buenos Aires, Argentina: Editorial Proyección.

Adorno, T. W. (1973). La disputa del positivismo en la sociologia alemana. Barcelona, Espanha: Ediciones Grijalbo. (Trabalho original publicado em 1969)

Adorno, T. W. (1995). Palavras e sinais: modelos críticos 2. Rio de Janeiro, RJ: Vozes. (Trabalho original publicado em 1969)

Adorno, T. W. (1995). Educação e emancipação (L. M. Wolfgan, trad.). Rio de Janeiro, RJ: Paz e Terra. (Trabalho original publicado em 1971)
Adorno, T. W. (1999). Textos escolhidos. São Paulo, SP: Nova Cultural.

Ardoino, J. (1996). Opium et camomille. À propos d'une épistémologie en acte! In J.-P. Escriva \& H. Vaugrand, L'opium sportif: la critique radicale du sport de l'estrême gauche à Quel Corps? Paris, France: L'Harmattan.

Arnoud, P. (Org.). (1996). Texto de apresentação da Collection Espaces et Temps du sport. In J.-P. Escriva \& H. Vaugrand, L'opium sportif: la critique radicale du sport de l'estrême gauche à Quel Corps? Paris, France: L'Harmattan. 
Berthaud, G. (1996). Le sport c'est l'ordre. In J.-P. Escriva $\&$ H. Vaugrand, L'opium sportif: la critique radicale $d u$ sport de l'estrême gauche à Quel Corps? Paris, France: L'Harmattan.

Berthaud, G.; \& BROHM, J.-M. (1978). Presentación. In Partisans: Deporte, cultura y represión. Barcelona, Espanha: Editorial Gustavo Gili. (Trabalho original publicado em 1972).

Brohm, J.-M. (1975). Corps et politique. Paris, France: Editions Universitaires.

Brohm, J.-M. (1992). Sociologie politique du sport. Nancy, France: Presses Universitaires de Nancy. (Trabalho original publicado em 1976)

Brohm, J.-M. (1995a). La théorie critique de l'institution sportive. In F. Baillette, \& J.-M. Brohm, Quel Corps? Critique de la modernité sportive. Paris, France: Éditions de la Passion.

Brohm, J.-M. (1995b). Olympisme et national-socialisme: un exemple de collaboration politique. In F. Baillette, \& J.-M. Brohm, Quel Corps? Critique de la modernité sportive. Paris, France: Éditions de la Passion.

Brohm, J.-M. (1996). Élements pour une sociologie politique du sport. In J.-P. Escriva \& H. Vaugrand, L'opium sportif: la critique radicale du sport de l'estrême gauche à Quel Corps? Paris, France: L'Harmattan.

Casco, R. (2003). As cicatrizes do corpo (Dissertação de Mestrado). Instituto de Psicologia da Universidade de São Paulo, São Paulo.

Daolio, J. (1995). Da cultura do corpo. Campinas, SP: Papirus.

Ellul, J. (1995). Sport et technique. In F. Baillette, \& J.-M. Brohm, Quel Corps? Critique de la modernité sportive. Paris, France: Éditions de la Passion.

Ellul, J. (1996). Le sport. In: L'opium sportif. In: J.-P. Escriva $\&$ H. Vaugrand, L'opium sportif: la critique radicale $d u$ sport de l'estrême gauche à Quel Corps? Paris, France: L'Harmattan.

Escriva, J.-P. \& Vaugrand, H. (1996). La critique radicale du sport: un devenir. In J.-P. Escriva, \& H. VAUGRAND,
L'opium sportif. La critique radicale du sport de l'estrême gauche à Quel Corps? Paris, France: L'Harmattan.

Freud, S. (1997). O mal-estar na civilização. Rio de Janeiro, RJ: Imago. (Trabalho original publicado em 1929)

Gantheret, F. (1978). Psicoanálisis institucional de la educación física y los deportes. In Partisans: Deporte, cultura y represión. Barcelona, Espanha: Editorial Gustavo Gili. (Trabalho original publicado em 1972)

Horkheimer, M. \& Adorno, T. W. (1973). Temas básicos da Sociologia. São Paulo, SP: Cultrix. (Trabalho original publicado em 1956)

Horkheimer, M. \& Adorno, T. W. (1985). Dialética do esclarecimento. Rio de Janeiro, RJ: Zahar. (Trabalho original publicado em 1947)

Horkheimer, M. (1998). Noveaux modèles dans les relations sociales. In Cahiers de l'IRSA: L'illusion sportive, sociologie d'une idéologie totalitaire (Vol. 2). Montpellier: Institut de Recherches Sociologiques et Anthropologiques. (trabalho original publicado em 1964)

Laguillaumie, P. (1996). Pour une critique fondamentale du sport. In J.-P. Escriva, \& H. Vaugrand, L'opium sportif: la critique radicale du sport de l'estrême gauche à Quel Corps? Paris, France: L'Harmattan.

Marcuse, H. (1963). Eros et civilization. Paris, France: Éditions de Minuit.

Quel Corps? (1976). Contribution a la critique du sport: Pierre de Coubertin [numéro special]. Quel Corps? 4/5, 24-32.

Quel Corps? (1995). En finir avec la bastille sportive! In F. Baillete, \& J.-M. Brohm, (Orgs.), Quel Corps? Critique de la modernité sportive. Paris, France: Éditions de la Passion.

Stoezel, J. (1963). La pscychologie sociale. Paris, France: Flammarion. 